\title{
CORRESPONDÊNCIA
}

\section{TRATAMENTO DO ACIDENTE VASCULAR CEREBRAL}

Congratulo a Sociedade Brasileira de Doenças Cerebrovasculares pelo excelente esforço em compilar de forma pragmática e colocar em nível nacional recomendações para o tratamento do acidente vascular cerebral ${ }^{1}$. Causou-me surpresa, no entanto, não ver mencionada a neurointervenção como opção terapêutica, já que técnicas endovasculares certamente têm lugar no combate a essa terrível moléstia; não só na sua forma hemorrágica, mas também isquêmica. Trata-se, pois, de técnicas estabelecidas e de amplo uso, não mais de meros "tratamentos contraditórios". O resultado obtido com angioplastia e colocação de stent em mais de 5200 carótidas, em diversos centros da América do Norte, América do Sul, Europa eÁsia, por exemplo, mostra um sucesso técnico em mais de $98 \%$, uma mortalidade de 0,84\% em 30 dias e uma incidência total de acidente vascular isquêmico de $3,9 \%^{2}$. Na verdade, muito semelhante aos da endarterectomia, porém com uma morbidade significativamente menor.

Em muitos centros aqui nos Estados Unidos, essa modalidade vem se constituindo em tratamento de escolha para pacientes com estenoses de difícil acesso cirúrgico, pacientes com patologia não aterosclerótica e para aqueles com elevado risco operatório. Do mesmo modo, o PROACT II mostrou ser possível ampliar o tempo de que se dispõe para salvar o tecido na área de penumbra ${ }^{3}$. O uso intra-arterial de trombolíticos, cumpre sublinhar, pode ser o único recurso disponível para o tratamento do acidente vascular cerebral isquêmico que complica o período pós-operatório ${ }^{4}$, visto ser a cirurgia recente consi-

\section{Resposta do Autor}

Inicialmente gostaria de agradecer o interesse do colega Edgard Pereira a respeito do Consenso Brasileiro do Tratamento do Acidente Vascular Cerebral (AVC), trabalho da Sociedade Brasileira de Doenças Cerebrovasculares (SBDCV) e dos proveitosos comentários. Neste trabalho não foi colocado o papel da neurorradiologia intervencionista que pode (ou deve) ser perfeitamente indicada no tratamen- derada critério de exclusão para trombólise endovenosa. Ademais, cerca de $20 \%$ a $30 \%$ dos vasoespasmos decorrentes de hemorragia subaracnoidea são refratários à "terapia dos 3 Hs". É precisamente neste ponto que a neurointervenção revela seu significativo potencial, reduzindo em $16 \%$ a mortalidade neste grupo de pacientes 5 . Estas ponderações, oportuno registrar, não têm a intenção de menosprezar o valor e o propósito do documento elaborado pela Sociedade; apenas visam ressaltar a importância e a necessidade de um trabalho interdisciplinar.

Somente a estreita colaboração entre as várias especialidades que, de alguma maneira, ocupam-se do problema, entendo, logrará estender o êxito no tratamento dos pacientes com acidente vascular cerebral. Por estas razões, penso ser contraprodutivo - e injustificável - excluir o neurointervencionista desse processo.

\section{REFERÊNCIAS}

1. Gagliardi RJ, et al. Primeiro consenso brasileiro do tratamento da fase aguda do acidente vascular cerebral. Sociedade Brasileira de Doenças Cerebrovasculares. Arq. Neuropsiquiatr 2001;59:972-980.

2. Wholey MH, et al. Global experience in cervical carotid artery stent placement. Cath Cardiovasc Intervent 2000;50:160-167.

3. Furlan A, et al. Intra-arterial prourokinase for acute ischemic stroke the PROACT II study: a randomized controlled trial. JAMA 1999;282: 2003-2011.

4. Chalela JA, et al. Safety of intra-arterial thrombolysis in the postoperative period. Stroke 2001;32:1365-1368.

5. Johnson SC. Effect of endovascular services and hospital volume on cerebral aneurysm outcome. Stroke 2000;31:111-117.

Edgard Pereira, MD Diretor, Serviço de Neurointervenção Universidade de Louisville, Louisville, Kentucky, USA 413 Courtfield Avenue Winchester, VA 22601 USA

to do AVC, (principalmente na doença carotídea, malformações ou no uso do trombolítico intra-arterial) pelos motivos abaixo expostos.

Quanto a doença carotídea, o consenso se limitou a abordar o tratamento da fase aguda do AVC, sabendo-se que as grandes indicações da angioplastia e/ou "stent" são para a prevenção, nos casos de estenose arterial significativa. 
Em relação ao tratamento das malformações, a sua correção, quando indicada na fase aguda, deixa de ser um procedimento estritamente clínico, e por este motivo não foi incluído neste consenso. Devido às características abrangentes deste trabalho, não seria possível citar todas as formas específicas de tratamentos para situações peculiares.

No tocante ao emprego da trombólise intra-arterial, através da neurorradiologia intervensionista, é um assunto que apesar de ser altamente entusiasmante e visto com bastante otimismo, ainda é controverso. Por este motivo, não foi incluído neste consenso, que procurou se alicerçar em fatos solidamente comprovados, para então indicar a sua prática clínica. Furlan ${ }^{1}$ (Cleveland Clinic), em recente conferência durante o 53th "Annual Meeting" da "American Academy of Neurology", cita que o PROACT II foi o único ensaio clínico que mostrou eficácia com o uso do trombolítico intra-arterial. Vários outros estudos tem sido desenvolvidos desde 1994. A "American Heart Association" (AHA) publicou, em 1996, recomendações ao uso dos trombolíticos no infarto cerebral e cita que, baseando-se em evidências científicas disponíveis até o momento, considera que a trombólise intra-arterial deve ser considerada como método de pesquisa em ensaios clínicos². Zaidat e $\mathrm{col}^{3}{ }^{3}$, em recente trabalho, analisando o potencial deste procedimento em dissecções carotídeas, cita as vantagens deste método, mas lembra que maio- res estudos são necessários para comprovar a sua eficácia e segurança. Por ser um assunto ainda controverso, não foi incluído neste consenso.

A Sociedade Brasileira de Doenças Cerebrovasculares tem se postado francamente favorável à neurorradiologia intervencionista, tem incentivado a sua prática e com freqüência incluído este temas em suas discussões, publicações, congressos e simpósios. Concordamos com a necessidade de equipes multidisciplinares e com a grande contribuição que a neurorradiologia intervensionista tem trazido.A SBDCV tem incentivado a formação de unidades "Stroke" que deve obrigatoriamente contar com os préstimos dos colegas especializados em intervenção neuroradiológica.

\section{REFERÊNCIAS}

1. Furlan AJ. Intra-arterial thrombolysis in acute ischemic stroke. Syllaboon-CD-ROM, 53th Annual Meeting American, Academy of Neurology 2001;3FC.007.90-103

2. Adams HP, Brott TC, Furlan AJ, et al. Guidelines for thrombolytic therapy for acute stroke: a supplement to the Guidelines for the Management of Patients with Acute Ischemic Stroke, a Statement for Healthcare Professionals from a Special Writing Group of the Stroke Council, American Heart Association. Circulation 1996;94:1167-1174.

3. Zaidat OO, Fernandes-Filho JAM, Singh G, Suarez JI. Thrombolytic therapy for acute extracranial artery dissection. Arq Neuropsiquiatr 2001;59:936-938.

Rubens José Gagliardi Sociedade Brasileira de Doenças Cerebrovasculares Avenida Angélica 916 / 305 01228-000 São Paulo SP

CORRESPONDÊNCIA. Esta seção de Arquivos de Neuro-Psiquiatria divulga opiniões e observações construtivas acerca de artigos publicados em seus últimos números. São aceitas cartas assinadas, sucintas e desprovidas de caráter pessoal, abordando aspectos objetivos dos artigos e utilizando até cinco referências bibliográficas.

Enviar sua contribuição em uma via acompanhada do respectivo disquete. Utilizar o endereço: Arquivos de Neuro-Psiquiatria Correspondência, Praça Amadeu Amaral 47 / 33, 01327-010 São Paulo SP. 